\title{
Comparative study of metabolic profile of women presenting with polycystic ovary syndrome in relation to body mass index
}

\author{
Akshaya S.*, Ratnaboli Bhattacharya \\ Department of Obstetrics and Gynaecology, Kasturba Hospital, Delhi, India \\ Received: 24 June 2016 \\ Accepted: 29 June 2016 \\ *Correspondence: \\ Dr. Akshaya S., \\ E-mail: akshayadr2010@gmail.com \\ Copyright: ( ) the author(s), publisher and licensee Medip Academy. This is an open-access article distributed under \\ the terms of the Creative Commons Attribution Non-Commercial License, which permits unrestricted non-commercial \\ use, distribution, and reproduction in any medium, provided the original work is properly cited.
}

\begin{abstract}
Background: Polycystic ovary syndrome (PCOS) is characterized by hyperandrogenism, ovulatory dysfunction and polycystic ovaries (PCO). The objective was to study and compare the metabolic effects of PCOS in lean PCOS (BMI <23) and obese PCOS (BMI > 23).

Methods: Fifty healthy women who were euthyroid with age range 15-38 years who presented to gynecology OPD and diagnosed to have PCOS according to ESHRE/ASRM criteria were included in the study. BMI (body mass index) was calculated by the formula weight in $\mathrm{kg} / \mathrm{height}$ in meter square. BMI were calculated were divided into 2 groups. Lean PCOS found in patients with BMI $<23 \mathrm{~kg} / \mathrm{m}^{2}$ and overweight/obese PCOS found in patients with BMI $>23 \mathrm{~kg} / \mathrm{m}^{2}$.

Results: Hypertension, deranged lipid profile, insulin resistances were frequently seen in obese PCOS than in lean PCOS. Deranged GTT (glucose tolerance test) was not statistically significant in these two groups $\mathrm{p}=0.15$.

Conclusions: The study concludes that obese PCOS were at higher risk of developing hypertension, deranged lipid profile and insulin resistance than lean PCOS as obesity is significant contributor to metabolic syndrome. Glucose intolerance was present in both obese and lean PCOS.
\end{abstract}

Keywords: PCOS, Hypertension, Lipid profile, Insulin resistance, GTT, MBS

\section{INTRODUCTION}

Polycystic ovary syndrome (PCOS) was first reported in modern medical literature by Stein and Leventhal who, in 1935, described seven women suffering from amenorrhea, hirsutism, and enlarged ovaries with multiple cysts. It is now recognized as a common heterogeneous, heritable disorder affecting women throughout their lifetime. ${ }^{1}$ The consequences of PCOS extend beyond the reproductive axis; as women with this syndrome are at substantial risk of developing metabolic syndrome. " "Metabolic syndrome" (MBS) is a constellation of cardiovascular disease risk factors associated with insulin resistance, glucose intolerance, dyslipidemia, hypertension and central obesity. ${ }^{2,3}$ Although much remains unknown regarding the underlying pathophysiology of PCOS, a form of insulin resistance intrinsic to the syndrome appears to play a central role in its development. Among many women with PCOS, the observed insulin resistance is partially explained by excess adiposity; however it is increasingly recognized that even lean women PCOS have increased insulin resistance compared to normal controls. ${ }^{4}$ Considering the relationship between insulin resistance and obesity, the relative contribution of these two parameters to the endocrinometabolic disturbances of PCOS and their impacts on hyperandrogenism and chronic anovulation are pivotal in understanding of this complex syndrome, which has not been clearly elucidated. It is recognized that BMI could be an important determinant. Nevertheless, the differential impact of insulin resistance and obesity on the disorders of the syndrome needs to be highlighted. ${ }^{5}$ 
The objective was to study and compare the metabolic effects of PCOS in lean PCOS (BMI <23) and obese PCOS (BMI >23).

\section{METHODS}

This observational cross sectional study was conducted in the department of gynaecology at Kasturba hospital Delhi, India. Total fifty patients who attended gynecology OPD and met the inclusion criteria were enrolled in the study. BMI were calculated were divided into 2 groups.

Group A (lean PCOS): Patients with BMI $<23 \mathrm{~kg} / \mathrm{m}^{2}$

Group B (overweight/obese PCOS): Patients with BMI $>23 \mathrm{~kg} / \mathrm{m}^{2}$

Women of age range 15-38 years diagnosed to have PCOS according to ESHRE/ASRM criteria were included in the study after obtaining a written informed consent.

\section{Exclusion criteria}

Other causes of hyperandrogenism, patient who have received any medication known to affect carbohydrate metabolism for at least 3 months before the study, Women using oral contraceptive pills, pregnancy and lactation and hypothyroidism.

Blood pressure was measured and lipid profile (HDL, LDL, triglycerides, total cholesterol), $75 \mathrm{~g}$ oral glucose tolerance test (fasting blood sugar and $2^{\text {nd }}$ hour post prandial), insulin resistance by HOMA-IR were done in all patients.

\section{Statistical evaluation}

Statistical evaluation was done by using SPSS (statistical package of the social sciences). Qualitative variables were expressed as numbers and percentages while quantitative variables were expressed as means. P-value less than 0.05 was considered as significant.

\section{RESULTS}

Out of 50 women were diagnosed to have PCOS according to ESHRE/ASRM criteria, there were more obese or overweight women $(56 \%)$ with BMI >23 and mean BMI of $29.52 \pm 2.43$. There were $44 \%$ who were lean with BMI $<23$ and mean BMI of lean $21.87 \pm 1.19$ (Table 1).

Table 1: Distribution of women with PCOS according to BMI.

\begin{tabular}{|c|c|c|c|c|c|c|}
\hline \multirow[t]{2}{*}{ BMI } & \multicolumn{2}{|l|}{ Total } & \multicolumn{2}{|c|}{$\begin{array}{l}\text { Lean PCOS } \\
\text { BMI }<23 \mathrm{~kg} / \mathrm{m}^{2} \text { (Group A) }\end{array}$} & \multicolumn{2}{|c|}{$\begin{array}{l}\text { Obese PCOS } \\
\text { BMI } \geq 23 \mathrm{~kg} / \mathrm{m}^{2} \text { (Group B) }\end{array}$} \\
\hline & No & $\%$ & No & $\%$ & No & $\%$ \\
\hline $18-23 \mathrm{~kg}$ & 22 & $44 \%$ & 22 & $44 \%$ & 0 & $0 \%$ \\
\hline $23.1-28 \mathrm{~kg}$ & 10 & $20 \%$ & 0 & $0 \%$ & 10 & $20 \%$ \\
\hline$>28 \mathrm{~kg}$ & 18 & $36 \%$ & 0 & $0 \%$ & 18 & $36 \%$ \\
\hline Number of patients & 50 & $100 \%$ & 22 & $44 \%$ & 28 & $56 \%$ \\
\hline Mean BMI & $25.90 \pm 4.58$ & & 21.8 & & 29. & \\
\hline
\end{tabular}

The women in obese group were of older age, belonging to higher socioeconomic status than the lean. The mean age of all PCOS women of our study was 24.98 years. The mean age group of lean PCOS and obese PCOS women was $23.32 \pm 3.14$ years and $26.28 \pm 4.18$ years respectively.

\section{Blood pressure}

9 (18\%) PCOS women had systolic B.P >130 mmHg out of whom $9(32.1 \%)$ were all obese PCOS. $10(20 \%)$ PCOS women had diastolic B.P > $85 \mathrm{mmHg}$ out of whom $10(35.7 \%)$ were all obese PCOS.

The mean systolic B.P of all the PCOS women was $120.76 \pm 8.95 \mathrm{mmHg}$. The mean systolic BP of lean PCOS and obese PCOS was $116.36 \pm 1.92 \mathrm{mmHg}$ and $124.21 \pm 10.70 \mathrm{mmHg}$ respectively. The difference of systolic BP was statistically significant between the two groups. $\mathrm{P}$-value $=0.001$ ( statistically significant).

The mean diastolic B.P was $75.48 \pm 6.41 \mathrm{~mm} \mathrm{Hg}$. The mean diastolic BP of lean PCOS and obese PCOS was $73 \pm 3.07 \mathrm{mmHg}$ and $77.43 \pm 7.64 \mathrm{mmHg}$ respectively. The difference of diastolic BP was statistically significant between the two groups. P-value $=0.014$ (statistically significant). 12 (24\%) PCOS women had mild hypertension and all the $12(42.9 \%)$ were obese PCOS. (Table 2, 3).

\section{Lipid profile}

$14(28 \%)$ PCOS women had deranged lipid profile out of whom $3(13.6 \%)$ were lean PCOS and 11 (39.3\%) were obese PCOS. 
The difference of deranged lipid profile was statistically significant between the two groups. Pvalue $=0.045$ (statistically significant) (Table 4).

$35(70 \%)$ of PCOS women had normal GTT out of which $18(81.8 \%)$ were lean and $17(60.8 \%)$ were obese PCOS.
$12(24 \%)$ of PCOS women had impaired GTT out of which $4(18.2 \%)$ were lean and $8(28.6 \%)$ were obese. $3(6 \%)$ of PCOS women were diabetic and these $3(10.7 \%)$ were all obese. The difference of deranged glucose tolerance test was not statistically significant. $\mathrm{P}$ value $=0.15$ (statistically not significant).

Table 2: Profile of blood pressure in women with PCOS.

\begin{tabular}{|c|c|c|c|c|c|c|c|}
\hline Blood pressure & \multicolumn{2}{|l|}{ Total } & \multicolumn{2}{|c|}{ Group A (lean PCOS) } & \multicolumn{2}{|c|}{ Group B (obese PCOS) } & \multirow{6}{*}{$P$-value $=0.001$} \\
\hline & Number & $\%$ & Number & $\%$ & Number & $\%$ & \\
\hline \multicolumn{7}{|l|}{$\mathrm{SBP}(\mathrm{mmHg})$} & \\
\hline$<120$ & 41 & $82 \%$ & 22 & $100 \%$ & 19 & $67.9 \%$ & \\
\hline $120-130$ & 0 & $0 \%$ & 0 & $0 \%$ & 0 & $0 \%$ & \\
\hline$>130$ & 9 & $18 \%$ & 0 & $0 \%$ & 9 & $32.1 \%$ & \\
\hline Mean SBP & \multicolumn{2}{|c|}{$120.76 \pm 8.95$} & \multicolumn{2}{|c|}{$116.36 \pm 1.92$} & \multicolumn{2}{|c|}{$124.21 \pm 10.70$} & \multirow{6}{*}{$P$-value $=0.014$} \\
\hline \multicolumn{7}{|l|}{$\mathrm{DBP}(\mathrm{mmHg})$} & \\
\hline$<80$ & 39 & $78 \%$ & 21 & $95.5 \%$ & 18 & $64.3 \%$ & \\
\hline $80-85$ & 1 & $2 \%$ & 1 & $4.5 \%$ & 0 & $0 \%$ & \\
\hline$>85$ & 10 & $20 \%$ & 0 & $0 \%$ & 10 & $35.7 \%$ & \\
\hline Mean DBP & \multicolumn{2}{|c|}{$75.48 \pm 6.41$} & $73.00 \pm 3.0$ & & \multicolumn{2}{|c|}{$77.43 \pm 7.64$} & \\
\hline
\end{tabular}

Table 3: Degree of hypertension in women with PCOS.

\begin{tabular}{|llll|}
\hline Hypertension & Total & $\begin{array}{l}\text { Group A } \\
\text { (lean } \\
\text { PCOS) }\end{array}$ & $\begin{array}{l}\text { Group B } \\
\text { (obese } \\
\text { PCOS) }\end{array}$ \\
\hline Normotensive & $38(76 \%)$ & $22(100 \%)$ & $16(57.1 \%)$ \\
\hline $\begin{array}{l}\text { Mild } \\
(\mathrm{BP}>130 / 85)\end{array}$ & $12(24 \%)$ & 0 & $12(42.9 \%)$ \\
\hline $\begin{array}{l}\text { Severe } \\
(\mathrm{BP}>160 / 100)\end{array}$ & 0 & 0 & 0 \\
\hline
\end{tabular}

$1(3.6 \%)$ of obese PCOS had FBS $>125 \mathrm{mg} / \mathrm{dl}$ (diabetes) and none of the lean was diabetic. $2(7.2 \%)$ of obese PCOS had $2^{\text {nd }}$ hour pp $>200 \mathrm{mg} / \mathrm{dl}$ and none of the lean was diabetic. The mean FBS of lean and obese PCOS women was $87.23 \pm 5.81$ and $86.86 \pm 13.18 \mathrm{mg} / \mathrm{dl}$ respectively. The mean $2^{\text {nd }}$ HR PP of lean and obese was $115.45 \pm 11.09 \mathrm{mg} / \mathrm{dl}$ and $120.93 \pm 18.78 \mathrm{mg} / \mathrm{dl}$ respectively. The difference of FBS and $2^{\text {nd }}$ HR PP was not statistically significant between the two groups (Table 6).
Table 4: Deranged lipid profile in women with PCOS.

\begin{tabular}{|c|c|c|c|c|c|}
\hline & \multicolumn{2}{|c|}{$\begin{array}{l}\text { Group A } \\
\text { (lean } \\
\text { PCOS) }\end{array}$} & \multicolumn{2}{|c|}{$\begin{array}{l}\text { Group B } \\
\text { (obese PCOS) }\end{array}$} & \multirow[t]{2}{*}{$\begin{array}{l}p- \\
\text { value }\end{array}$} \\
\hline & No & $\%$ & No & $\%$ & \\
\hline $\begin{array}{l}\text { Deranged } \\
\text { lipid profile }\end{array}$ & 3 & $13.6 \%$ & 11 & $39.3 \%$ & 0.45 \\
\hline $\begin{array}{l}\text { Mean HDL } \\
(\mathrm{mg} / \mathrm{dl})\end{array}$ & \multicolumn{2}{|c|}{$56.27 \pm 5.17$} & \multicolumn{2}{|c|}{$52.89 \pm 7.65$} & 0.082 \\
\hline $\begin{array}{l}\text { Mean LDL } \\
(\mathrm{mg} / \mathrm{dl})\end{array}$ & \multicolumn{2}{|c|}{$128.22 \pm 14.03$} & \multicolumn{2}{|c|}{$141.43 \pm 24.12$} & 0.027 \\
\hline $\begin{array}{l}\text { Mean } \\
\text { triglyceride } \\
(\mathrm{mg} / \mathrm{dl})\end{array}$ & \multicolumn{2}{|c|}{$123.18 \pm 14.73$} & \multicolumn{2}{|c|}{$139.93 \pm 28.17$} & 0.015 \\
\hline $\begin{array}{l}\text { Mean } \\
\text { cholesterol } \\
(\mathrm{mg} / \mathrm{dl})\end{array}$ & \multicolumn{2}{|c|}{$176.50 \pm 16.92$} & \multicolumn{2}{|c|}{$201.46 \pm 36.91$} & 0.005 \\
\hline
\end{tabular}

Table 5: GTT profile in women with PCOS.

\begin{tabular}{|llllllll|}
\hline \multirow{2}{*}{ GTT } & Total & & Group A (lean PCOS) & \multicolumn{2}{c|}{ Group B (obese PCOS) } & P-value \\
\hline Normal GTT & No & $\%$ & No & $\%$ & No & $\%$ & \\
\hline Impaired GTT & 35 & 70 & 18 & 81.8 & 17 & 60.8 & 0.15 \\
\hline Diabetes & 12 & 24 & 4 & 18.2 & 8 & 28.6 & 10.7 \\
\hline
\end{tabular}


Table 6: FBS and $2^{\text {nd }}$ HR PP in PCOS.

\begin{tabular}{|c|c|c|c|c|c|}
\hline & \multicolumn{2}{|c|}{ Lean PCOS } & \multicolumn{2}{|c|}{ Obese PCOS } & \multirow{2}{*}{ p-value } \\
\hline & Number & $\%$ & Number & $\%$ & \\
\hline FBS $>125 \mathrm{mg} / \mathrm{dl}$ & 0 & 0 & 1 & $3.6 \%$ & \\
\hline $2^{\mathrm{ND}} \mathrm{HR}$ PP>200 mg/dl & 0 & 0 & 2 & $7.2 \%$ & \\
\hline Mean FBS & $87.23 \pm 5$ & & $86.86 \pm 1$ & & 0.903 \\
\hline Mean $2^{\text {nd }} \mathrm{HR}$ & $115.45 \pm$ & & $120.93 \pm$ & & 0.168 \\
\hline
\end{tabular}

Independent of obesity per se, PCOS is associated with higher prevalence of insulin resistance, impaired glucose tolerance and type 2 diabetes as evident by a higher incidence of deranged GTT, high HOMA-IR score (> 2.5) and high $\mathrm{HbAlc}(>6.5)$ in both groups with comparable values. The fasting insulin level was higher in obese group $(13.58 \mu \mathrm{IU} / \mathrm{ml})$ than in lean group $(11.3 \mu \mathrm{IU} / \mathrm{ml})$. P-value $\leq 0.001$ (statistically significant). $88 \%$ of all PCOS were insulin resistant (HOMA-IR $>2.5$ ) with a preponderance in obese women (Table 7).

Table 7: Insulin and other metabolic features of PCOS.

\begin{tabular}{|c|c|c|c|}
\hline & $\begin{array}{l}\text { Group A } \\
\text { lean PCOS }\end{array}$ & $\begin{array}{l}\text { Group B } \\
\text { obese PCOS }\end{array}$ & $\begin{array}{l}\text { p- } \\
\text { value }\end{array}$ \\
\hline $\begin{array}{l}\text { Fasting insulin } \\
>10 \mathrm{Miu} / \mathrm{ml}\end{array}$ & 86.4 & 89.29 & \\
\hline $\begin{array}{l}\text { Mean fasting } \\
\text { insulin }\end{array}$ & $11.30 \pm 1.91$ & $13.58 \pm 2.15$ & $<0.001$ \\
\hline $\begin{array}{l}\text { Fasting } \\
\text { insulin:glucose } \\
\text { ratio }\end{array}$ & $0.13 \pm 0.02$ & $0.15 \pm 0.03$ & 0.001 \\
\hline HOMA-IR>2.5 & 86.4 & 89.3 & 0.009 \\
\hline $\begin{array}{l}\text { Mean HOMA- } \\
\text { IR }\end{array}$ & $2.44 \pm 0.45$ & $2.93 \pm 0.75$ & \\
\hline Mean $\mathrm{HbA1c}$ & $5.19 \pm 0.30$ & $6.18 \pm 0.48$ & \\
\hline $\mathrm{HbA1c}<5.7$ & 0 & 2 & \\
\hline HbA1c 5.7-6.5 & 18 & 21 & 0.363 \\
\hline HbA1c 6.5 & 4 & 5 & \\
\hline
\end{tabular}

\section{DISCUSSION}

The manifestations of PCOS are not confined to the gynaecological sphere; women afflicted by this disease show an increased prevalence of several co-morbidities, including obesity, dyslipidemia, hypertension, metabolic syndrome and type $2 \mathrm{DM}$ in comparison with women without PCOS. These features along with other alterations underlie the greater risk of developing cardiovascular disease and all-cause mortality observed in these subjects. ${ }^{6}$

The prevalence of obesity varies in these women, and in present study bit was more common as $56 \%$ were found to be obese/overweight with BMI $>23 \mathrm{~kg} / \mathrm{m}^{2}$ which is similar to study done by Saxena P et al $(58 \%) .^{7}$ Asian Indians have higher percentage body fat, abdominal obesity at lower or similar levels of BMI levels as compared to white Caucasians. Asians are more predisposed to develop insulin resistance and cardiovascular risk factors at lower levels of BMI as compared to other ethnic groups. ${ }^{8}$

Obese PCOS usually presents in older age group than lean PCOS as in the present study, mean age was higher in obese group (26.28 \pm 4.18 years) than in lean group (23.32 \pm 3.14 years). Morales AJ et al observed that the mean age of lean PCOS was $26.7 \pm 1.9$ years and obese PCOS was $27.9 \pm 2.1$ years which is comparable to this study. ${ }^{9}$ PCOS was more common in obese women from affluent society than in lean women.

Independent of obesity and consistent with the increased insulin resistance, women with PCOS displayed an increased prevalence of impaired glucose tolerance and type 2 diabetes in this study as evident by a high incidence of deranged GTT, high HOMA-IR score $(>2.5)$ and high HbAlc (>6.5). Several studies have pinpointed insulin resistance (IR) as the fundamental link associating PCOS and metabolic syndrome, although IR may be present in PCOS independently of obesity. ${ }^{10}$ Boudreaux et al reported 5 fold risk of developing DM2 over a period of 8 years in women with PCOS, compared with the risk calculated using age and weight matched controls. ${ }^{11}$

The prevalence of mild hypertension was more in obese group than in lean group which is comparable with the other studies. ${ }^{12}$ Obese PCOS had significantly higher deranged lipid profile than the lean PCOS women. Holte $\mathrm{J}$ et al studied serum lipoprotein lipid profile in women with PCOS and their weight matched controls and observed obese women with PCOS had higher concentrations of total cholesterol, LDL, low HDL than in lean counterparts. But he also inferred that the atherogenic lipoprotein pattern is entirely accounted by obesity and there is no significant effect of PCOS or hyperinsulinism on lipoprotein profile. ${ }^{13}$

\section{CONCLUSION}

The present study reveals that obesity seen in $56 \%$ of observed patients plays an important role in metabolic alterations in women with polycystic ovarian syndrome. The consequences of PCOS extend beyond reproductive axis. Hyperinsulinemia and glucose intolerance were present in both lean and obese PCOS, but obesity aggravates the underlying insulin resistance as judged by a higher HOMA-IR score in obese PCOS. Metabolic abnormalities like hypertension and deranged lipid profile 
and the concurrent cardiovascular health risks were more frequently observed in obese PCOS. Thus they are at substantial risk of developing metabolic syndrome and obesity was a significant contributor to its development.

Hence it is suggested that life style modification such as exercise and weight reduction and periodic monitoring should be done in all PCOS women and more so in obese. The most important aspect of long term care of PCOS is managing cardiovascular risks such as obesity, insulin resistance, diabetes, hypertension and elevated blood lipids.

\section{Funding: No funding sources}

Conflict of interest: None declared

Ethical approval: The study was approved by the Institutional Ethics Committee

\section{REFERENCES}

1. Rotterdam ESHRE/ASRM-Sponsored PCOS Consensus Workshop Group. 2004 Revised 2003 consensus on diagnostic criteria and long-term health risks related to polycystic ovary syndrome. Fertil Steril. 2004;81(1):19-25.

2. Ford ES, Giles WH, Dietz. WHO prevalence of metabolic syndrome among US adults: findings from the third national health and nutrition examination survey. J Am Med Asso. 2002;287:356-9.

3. Gambineri A, Pelusi C,Vicennati V, Pasquali R. obesity and polycystic ovary syndrome. Int J obes relat metab disodr 2002; 26:883-96

4. Dunaif A, Segal KR, Futterweit W. Profound peripheral insulin resistance, independent of obesity, in PCOS. 1989;38:1165-74.

5. Paradisi R, Venturoli S, Pasquali R. Effect of obesity on gonadotrophin secretion in patients with polycystic ovary disease. J Endocrinol Invest. 1986;9:139-44.
6. Wild RA. Long term health consequences of PCOS. Hum Reprod Update. 2002;8(3):231-41.

7. Saxena P, Prakash A, Nigam A, Mishra A. PCOS: is obesity a sine qua non? a clinical, hormonal and metabolic assessment in relation to BMI. Indian $\mathrm{J}$ Endocrinol Metab. 2012;16(6):996-9.

8. Mckeigue PM, Shah B, Marmot MG. Relation of central obesity and insulin resistance with high diabetes prevalence and cardiovascular risk in south Asians. Lancet. 1991;337:382-6.

9. Morales AJ, Laughlin GA, Butzow T, Maheshwari $\mathrm{H}$. Insulin, somatotropic and leutinizing hormone axes in lean and obese with PCOS: common and distinct features. J Clinical Endocrino Metab. 1996;81:8.

10. Toprak S, Yonem A, Cakir B. Insulin resistance in nonobese patients with polycystic ovary syndrome. Hormone Research. 2001;55(2):65-70.

11. Boudreaux MY, Talbott EO, Kip KE, Brooks MM, Witchel SF. Risk of T2DM and impaired fasting glucose among PCOS subjects; results of an 8 year follow up. Curr Diab Rep. 2006;6:77-83.

12. Joshi B, Mukherjee S, Patil A, Purandare A. A crosssectional study of polycystic ovarian syndrome among adolescent and young girls in Mumbai, India. Indian J Endocr Metab. 2014;18:317-24.

13. Holte J, Bergh T, Berne C, Berglund L, Lithell H. Enhanced early insulin response to glucose in relation to insulin resistance in women with polycystic ovary syndrome and normal glucose tolerance. J Clin Endocrinol Metab. 1994;78:1052-8.

Cite this article as: Akshaya S, Bhattacharya R. Comparative study of metabolic profile of women presenting with polycystic ovary syndrome in relation to body mass index. Int J Reprod Contracept Obstet Gynecol 2016;5:2561-5. 